\title{
Comparative study of metaphor in British and United States of America (US) political discourse
}

\author{
Igor Ivanovic
}

\section{DOI: 10.18355/XL.2017.10.02.02}

\begin{abstract}
Every speech is embellished by the metaphoric expression, despite its context, content, and tone. In different fields, the application of metaphors may vary, yet still they are used regardless the situation consciously or unconsciously. In the political discourse, metaphoric expressions play pivotal role serving as the instruments of persuasion, simplification, and demonstration. As the main purpose of a political figure to attract the followers by convincing them certain agenda is right, the literal meaning of words will be not enough for such goals. At the same time, political speech of different nations varies so as the utilization of metaphors. In this case, the present research aimed to analyse the British and American political discourse and to reveal if there are differences and similarities between them, how metaphors are applied, and in what way they are used for appealing to the public. The current research used inaugural speeches of American presidents and manifestos of British political parties from 1974 to 1997 for the analysis. By utilizing the Range for Sample Corpora program for dissecting the data, the study came to a conclusion that the British corpus contains fewer metaphors than the American one. American corpus is rich in religious metaphors and both corpora include the metaphors derived from source domains as authority, motion, and liberty.
\end{abstract}

Key words: political manifesto, metaphors, comparative analysis

\section{Introduction}

\subsection{Background of the Problem}

Figures of speech embellish language, sophisticate it, and provide additional meaning to words. It is possible to compare them with the seasonings of a dish, especially what concerns metaphors. Metaphoric expressions can appeal to a certain subject creating stimuli that refer to a cultural background or memories; they also can be used as the method of persuasion. Researchers define a metaphor claiming that it is "characterized by the conceptualization of one cognitive domain in terms of components more usually associated with another cognitive domain" (Taylor 1989: 132). Additionally, it is perceived as "a conceptual mapping from a source domain to a target domain, with both ontological correspondences and epistemic correspondences entailed by the mapping" (Yu 1998: 15). Overall, metaphoric expressions can be conceptualized as:

1) being concerned with a framework of ideas, where these frameworks are specifically designed;

2) being projective in the way of allowing to organize several layers of meaning of one word by focusing or shifting it to another (Schroots 1991).

Furthermore, metaphors are usually perceived as a representation of language, not the characteristic of thinking process or actions. Due to such reason, metaphors sometimes are considered to be as the figures of speech of secondary importance or appropriate to use only in certain subjects (Guttenplan 2005). However, metaphoric 
expressions are pervasive in speech as well as in thought and action. Of course, an abundance of metaphors in language can be appropriate only in certain situations and discussion of particular subjects, yet, in such field as the political speech it is crucial.

Politicians have to master not only oratory skills but also the ability to utilize relevant figures of speech. As the majority of the public figures tend to control the people's attitudes, application of appealing and germane metaphors are essential for the speech to gain its primary goal, namely to address the listeners. Whether it is needed to convince the voters, attract more supporters, or bring round the opponents, the political speech has to contain the metaphors that will be appealing to the listeners. Overall, the politicians rely heavily on the ability to convince masses through speech, which include oratory skills and efficient use of language. As it was revealed there is a strong connection between politics and language, where the last serve as the instrument for pursuing political or personal agenda (Chilton 2004).

As a result, metaphoric expressions in the political speech have a special status, as they have the ability to induce an emotional reaction from the listeners and serve as the method of persuasion (Mio 1997). Inaugural speeches and political manifestos are the most vivid representation of such practice because they are targeting the support of potential voters, thus, it is essential for the speech to be emotional, persuasive, and appealing. For instance, according to $\mathrm{Xu}$ (Xu 2010), in his speeches Bill Clinton applied a widely-used metaphor of Americans as travellers, like "for all of us are on that same journey of our lives", "our journey, too, will come to an end", and "but the journey of our America must go on" (p. 4). The same researcher claimed Richard Nixon utilized the similar metaphors ( $\mathrm{Xu} 2010)$. The symbolism of journey is encapsulated in the American history linking this metaphor to the foundation of the U.S. by the fist migrants.

There are a lot of other examples of utilization of metaphors in the political speeches, yet it is important to note that the metaphoric expressions serve as the representation of certain culture as well. At the same time, political discourse varies from country to country where the utilization of metaphors is distinctive as well.

\subsection{Aims and Objectives}

There are few studies exploring cultural differences in the metaphor from various corpora. After the initial evaluation of literature dedicated to this topic, it was revealed that such research is scarce. There are few inquiries analysing the metaphor distinctions in the corpora of two or three languages. In order to target such a gap, the present research aims to determine the cultural discrepancies between the British and American corpora of political speeches from 1974 to 1997. It is crucial to reveal if there are similarities or/and differences between these two corpora and how they appeal to the listeners of both countries.

\subsection{Research Questions}

The following research questions will be answered during the course of the present research:

(28) What are the cultural differences/similarities between the British and American corpora?

(29) What are the purposes the political officials following when using such metaphors?

(30) How such metaphors appeal to the American and British public?

\section{Theoretical Background}




\subsection{Metaphor Analysis}

Within the linguistic framework, the metaphor is identified as the notion of one conceptual area from the viewpoint of another conceptual field. For instance, when speaking, people usually perceive life as a journey, arguments as wars, or society as a plant; that is why metaphors have to be viewed not only as the part of the language but also the cognitive process and actions. According to Benoit (Benoit 2001), "unless the two ideas brought together in metaphor work on each other in some significant way, then apart from being merely ambiguous, metaphor would be either a succinct way of speaking, or, conversely, an elaborate way of speaking, since an extraneous idea is brought in where a single thought would do just as well" (p. 71). Metaphors are the expressions that have additional meaning or the double bottom.

The first researcher who conceptualized the notion of conveying two ideas together was I. A. Richards (Kövecses 2002). Richards called these two paradigms as tenor and vehicle, yet he did not propose any explicit definition of the mechanism between two domains. However, it is possible to suggest that the 'vehicle' here represents the concept transmitted by the literal meanings of the words applied metaphorically while 'tenor' is the concept encapsulated through the vehicle.

For the last several decades, the metaphorical expressions are viewed through the comparison theory rather than substitution framework where metaphors are viewed in terms of decoration to the core meaning. Several modern psychological and linguistic studies claim that metaphors have to be analysed as a comparison due to their character. Specifically, there is a view that metaphors can be dissected by its cognitive content. As it was mentioned earlier, while using metaphors, the speaker encapsulates in the word or expression a deeper meaning, in some cases consciously and sometimes unconsciously. For example, it is possible to say that someone fights as a lion, which means he/she is courageous and strong rather than being turned into a real animal. This metaphor derives from the animal world through comparison between an animal and human through some form of reverse anthropomorphism.

The intention to draw a line between the literal and metaphoric meaning is presupposed by the idea that cognitive sense will one way or another be given to literal meaning. Metaphor, in this case, tends to be a deviant utilization of language. Instead of eliminating the distinction, such point of view relativizes it (Mueller 2010). In this case, the cognitive element of literal meaning will not be separated from the metaphorical one. Following this perception of metaphor, a conflict emerges with Lakoff \& Johnson's (2003) statements that “our conceptual system is largely structured metaphorically, for past metaphors - now taken as literal - can generally be retrieved as metaphors" (p. 48). Extracting their metaphorical roots can improve the perception of metaphor as a concept while in other instances it makes the literal meaning ambiguous.

Earlier, Burke (Burke 1941) presented the vision towards metaphor as "perspective incongruity". The researcher internalizes the use of metaphors to categorizing by emphasizing that the category a speaker chooses when creating metaphor depends on his/her culture, personal interest, and social convention (Burke 1941). By applying metaphors in her/his speech, a speaker does not categorize the discrepancy observed in metaphor. This disparity stems from the fact that during metaphorisation the speakers are guided by particular interest distinctive from those presupposing usual categorization.

Metaphors are usually derived from common source domains that can be found in all languages and cultures, despite the fact that cultural metaphors can be of different meaning. Often, metaphoric expressions are retrieved from such source 
domains as human body (e.g. head of department), health (e.g. to hurt one's feelings), animals, plants (e.g. to plant an idea), construction (e.g. being in ruins), machines (e.g. to produce an argument), sports (e.g. to toy with idea), economics (e.g. to spend time), cooking (e.g. recipe for success), motion (e.g. making something step by step), emotion (e.g. burst with tears), and religion (e.g. sacrifice something) (Kövecses 2002). The source domains of metaphoric expressions are derived from the daily activities or from the constructs existing in nation, society, or culture. At the same time, in several cultures metaphors can be used in the same way. For example, Perez (Perez 2008) studied the utilization of metaphor 'love as a journey' in English, Spanish, Italian, German, and French languages producing the findings claiming that in all languages there is certain parallelism between 'love' and 'journey'. At the same time, not only cultural context designates the utilization of metaphors.

\subsection{Cultural Comparison}

As it was mentioned earlier, cultural analysis of metaphors is the essential part of the current study. For this purpose, the researcher has chosen the theory developed by Geert Hofstede, which synthesized all aspects and allocated several categories characterizing national culture (Hofstede 2006). Furthermore, Hofstede created six features designating every national culture regarding the levels of "femininity/masculinity, individualism/collectivism, power distance, uncertainty avoidance, indulgence, and long-term orientation" (Mooij \& Hofstede 2006: 183). Such framework enables the research with the number of characteristic features according to which the cultural analysis can be implemented.

\section{Materials and Methods}

\subsection{Research Design}

For the aims and objectives of the present research, qualitative research design was applied as the main framework. As the main aim of the current study is to analyse British and American corpora of political speech, it is believed that qualitative research design suits this purpose. First of all, this framework is implemented when the researcher tries to reveal the core of the problem and reveal why this issue emerges. As it corresponds with the goals of the present research, the qualitative design is implemented as the main framework. The issue explored in the current inquiry is evaluated from several angles, specifically, the analysis evaluates British and American corpora of metaphors used in the political speech, the factors designating the application of such metaphors, compares both corpora, and determines the cases when the metaphors are implemented.

\subsection{Data Collection}

Primary data included the British and American corpora of political speech. Specifically, it was decided to include inaugurals of the American presidents and manifestos of British political parties from 1974 to 1997. As Britain has different political structure, there were no inaugural speeches, which were replaced by the parties' manifestos. It was important to evaluate the data from the same time period and to collect the information that is similar in content and context. No additional data were included into the British and American corpora, recent inaugurals and political manifestos were disregarded due to the interest in the selected time period.

Secondary information was obtained by the collection of peer-reviewed journals and books dedicated to the issue of metaphor in political speech. The criteria for 
inclusion contained the analysis of time period of 1974-1997, evaluation of metaphor in general and within the framework of political speech, recent studies exploring the same themes, and credibility of all sources. New inquiries researching this topic were considered as additional material, but the results obtained by the analysis of a different time period were not taken into account.

\subsection{Sample}

To meet all requirements of the present research, the British Political Speech (BPS) corpus was developed based on British variant of English language materials that include the British political speeches from 1974 to 1997.12 party political manifestos of two British political parties, Conservative, and Labour were chosen for the analysis. American Political Speech (APS) corpus was created based on the American variant of English language materials that involved the inaugural speeches from 1974 to 1997. 6 materials were selected including the inaugural speeches of such U.S. presidents, as Bill Clinton, Ronald Reagan, George Bush and Jimmy Carter.

\subsection{Data Analysis}

Secondary data were analysed by selecting the most appropriate studies in the topic of metaphor and political speech. This information was dissected with the help of analytical and descriptive techniques by choosing the records relevant to the current topic. It was crucial to evaluate the most recent data and findings dedicated to the same time period of 1974 to 1997 . At the same time, several older sources were assessed in order to present a retrospective view towards metaphor in political speech.

Primary data were selected out of British and American political texts containing inaugural speeches and political manifestos, which were dissected by analytical tools. The language data in British political speech (BPS) and American political speech (APS) were processed by Range for Sample Corpora program to profile words in the frequency of their usage, coverage, and range. Frequency criterion is the main indicator for the purposes of current research, as BPS and APS are discipline-specific as well as it is crucial to determine what the most popular metaphors in a certain culture are. The frequency of utilization of metaphors and the range of their usage are analysed only by the Range program. The comparison of two corpora involves Hofstede framework that enabled the researchers to contrast BPS and APS within the cultural framework.

\subsection{Limitations and Delimitations}

It is possible to note that the limitations of the present research stemmed from the chosen design and the size of the sample. The qualitative design does not allow the research to evaluate a lot of materials and does not produce the relationship between variables. In addition, the study gathered a limited size of materials, especially what concerns American corpus. There is also an inconsistency between the size of the American and British sample, as there are only 6 inaugurals and 12 political manifestos. However, the present inquiry had the purpose of analysing the British and American corpora in a certain time period, which does not allow selecting more than 6 in American corpus or less than 12 in British one.

Additionally, there is a gap in academic research dedicated to the issue of metaphor in political speech. There are also certain discrepancies and lack of consensus among scholars regarding the topic, where it was difficult to find a balance. A lot of studies exploring these themes produced different findings that do not coincide with each other making the ability to create an objective conclusion to be difficult. At the 
same time, it is considered that neither of these limitations affected seriously the current study or compromised its credibility, reliability, and quality.

\section{Findings}

\subsection{General Assumptions}

British and American corpus was analysed using Range for Sample Corpora program that calculated the frequency and range of words in the materials. While analysing BPS and APS corpus, it was detected that BPS contains fewer metaphors than APS. British corpus included more material; the language of the political manifestos was not rich on metaphors and symbolism, and the language of BPS is straightforward and clear with the speakers rarely utilizing metaphoric expressions. Unlike BPS, American corpus was enriched with symbolism and metaphors, as the U.S. political speakers relied more on the rhetorical tools than on specifics. The difference between the BPS and APS was evident as well, as clear distinctions were recognized among the metaphors applied by British and U.S. speakers. Moreover, it was determined that the U.S. political speakers tend to appeal to ordinary citizens using plain and uncomplicated words and expressions while the British speakers operate with the complex and specific vocabulary. Furthermore, some certain parts of BPS could be understood by the highly educated public, as the speakers very often applied graphics, numbers, as well as economic and financial data.

\subsection{American Corpus}

The following table represents the most common themes used in the APS. Each column represents a theme, frequency, and example of utilization of a certain metaphor retrieved from the miscellaneous political speech of the American corpus. As several metaphors used by the speakers represent a common topic, it was decided to unite them into one group.

\begin{tabular}{|c|c|c|c|}
\hline Source Domain & Word & Frequency & Example \\
\hline \multirow{4}{*}{ Unity } & Together & 25 & \multirow{4}{*}{$\begin{array}{l}\text { "Let us create together a } \\
\text { new national spirit of unity } \\
\text { and trust" (Carter, 1977). } \\
\text { "Our greatest responsibility } \\
\text { is to embrace a new spirit of } \\
\text { community for a new centu- } \\
\text { ry" (Clinton, 1997). }\end{array}$} \\
\hline & Union & 10 & \\
\hline & Unity & 7 & \\
\hline & Community & 5 & \\
\hline \multirow{5}{*}{ Religion } & God & 20 & \multirow{5}{*}{$\begin{array}{l}\text { "God bless you and God } \\
\text { bless the United States of } \\
\text { America" (Bush, 1989). } \\
\text { "I will work, I will save, I } \\
\text { will sacrifice, I will en- } \\
\text { dure... (Reagan, 1981). } \\
\text { "Because we are free we can } \\
\text { never be indifferent to the }\end{array}$} \\
\hline & Faith & 13 & \\
\hline & Spirit & 13 & \\
\hline & Bless & 9 & \\
\hline & Sacrifice & 9 & \\
\hline
\end{tabular}

XLinguae Journal, Volume 10 Issue 2, April 2017, ISSN 1337-8384 


\begin{tabular}{|c|c|c|c|}
\hline & Prayer & 7 & \multirow{5}{*}{$\begin{array}{l}\text { fate of freedom elsewhere" } \\
\text { (Carter, 1977). }\end{array}$} \\
\hline & Oath & 5 & \\
\hline & Fate & 4 & \\
\hline & Compassion & 3 & \\
\hline & Prophet & 2 & \\
\hline \multirow{3}{*}{ Public } & Children & 18 & \multirow{3}{*}{$\begin{array}{l}\text { "There are the children who } \\
\text { have nothing, no love, no } \\
\text { normalcy" (Bush, 1989). }\end{array}$} \\
\hline & Citizens & 18 & \\
\hline & Fellow & 17 & \\
\hline \multirow{6}{*}{ Authority } & Strength & 19 & \multirow{6}{*}{$\begin{array}{l}\text { "To that effort I pledge all } \\
\text { my strength and every power } \\
\text { of my office" (Clinton, } \\
\text { 1997). } \\
\text { "It is our birth right as citi- } \\
\text { zens of this great Republic, } \\
\text { and we'll meet this chal- } \\
\text { lenge" (Reagan, 1985). }\end{array}$} \\
\hline & Power & 13 & \\
\hline & Force & 4 & \\
\hline & Authority & 3 & \\
\hline & Triumph & 3 & \\
\hline & Birth right & 2 & \\
\hline \multirow{8}{*}{ Values/freedom } & Freedom & 37 & \multirow{8}{*}{$\begin{array}{l}\text { "A new breeze is blowing, } \\
\text { and a nation refreshed by } \\
\text { freedom stands ready to push } \\
\text { on" (Bush, 1989). } \\
\text { "We have already found a } \\
\text { high degree of personal } \\
\text { liberty, and we are now } \\
\text { struggling to enhance equali- } \\
\text { ty of opportunity" (Carter, } \\
\text { 1977). }\end{array}$} \\
\hline & Democracy & 15 & \\
\hline & Peace & 15 & \\
\hline & Hope & 14 & \\
\hline & Opportunity & 12 & \\
\hline & Liberty & 10 & \\
\hline & Diversity & 5 & \\
\hline & Equal & 5 & \\
\hline \multirow{2}{*}{ Difficulties } & Challenge & 7 & \multirow{2}{*}{$\begin{array}{l}\text { "...we will meet this chal- } \\
\text { lenge" (Reagan, 1985). }\end{array}$} \\
\hline & Struggle & 4 & \\
\hline Devotion & Courage & 6 & “...we will strengthen our \\
\hline
\end{tabular}




\begin{tabular}{|c|c|c|c|}
\hline & Commitment & 4 & \multirow{3}{*}{$\begin{array}{l}\text { historic ties and assure them } \\
\text { of our support and firm } \\
\text { commitment" } \\
\text { 1981). }\end{array}$} \\
\hline & Patriotism & 2 & \\
\hline & Mission & 4 & \\
\hline \multirow{5}{*}{ Motion/transformation } & Change & 12 & \multirow{5}{*}{$\begin{array}{l}\text { "The greatest progress we } \\
\text { have made, and the greatest } \\
\text { progress we have yet to } \\
\text { make, is in the human heart" } \\
\text { (Clinton, 1997). } \\
\text { "And as we continue our } \\
\text { journey, we think of those } \\
\text { who travelled before us" } \\
\text { (Reagan, 1985). }\end{array}$} \\
\hline & Progress & 11 & \\
\hline & Journey & 8 & \\
\hline & Renew & 8 & \\
\hline & Revolution & 6 & \\
\hline
\end{tabular}

Table 1: APS

\subsection{British Corpus}

The following table represents BPS with the same segmentation, as it was presented in the Table 1:

\begin{tabular}{|c|c|c|c|}
\hline Source Domain & Word & Frequency & Example \\
\hline \multirow{5}{*}{ Community/public } & Labour & 791 & \multirow{5}{*}{$\begin{array}{l}\text { "Labour had built two mil- } \\
\text { lion houses in six years" } \\
\text { (Labour party, 1974). } \\
\text { "...both for the employees } \\
\text { and for the public at large' } \\
\text { (Conservative party, 1987). }\end{array}$} \\
\hline & Local & 489 & \\
\hline & Public & 482 & \\
\hline & Community & 307 & \\
\hline & Workers & 88 & \\
\hline \multirow{5}{*}{ Stimulation } & Support & 312 & \multirow{5}{*}{$\begin{array}{l}\text { "...by increasing govern- } \\
\text { ment support for the new } \\
\text { technologies" (Conservative } \\
\text { party, 1983). } \\
\text { "We will mount a concerted } \\
\text { effort to stimulate the devel- } \\
\text { opment..." (Labour party } \\
\text { 1979). }\end{array}$} \\
\hline & Encourage & 216 & \\
\hline & Stimulate & 14 & \\
\hline & Guidance & 11 & \\
\hline & Invest & 10 & \\
\hline \multirow{2}{*}{ Power/Authority } & Power & 164 & \multirow{2}{*}{$\begin{array}{l}\text { "... we are shifting power } \\
\text { and wealth back to working } \\
\text { families and away from the }\end{array}$} \\
\hline & Authorities & 163 & \\
\hline
\end{tabular}




\begin{tabular}{|c|c|c|c|}
\hline & Law & 144 & state" (Conservative party, \\
\hline & Order & 81 & "...we have the authority of \\
\hline & Royal & 17 & bour party, 1997). \\
\hline \multirow{6}{*}{ Liberty } & Freedom & 128 & \multirow{6}{*}{$\begin{array}{l}\text { "...to have more freedom of } \\
\text { choice about what they do } \\
\text { for themselves" (Conserva- } \\
\text { tive party, 1987). } \\
\text { "We will strengthen equality } \\
\text { before the law and equality } \\
\text { of opportunity" (Labour } \\
\text { party, 1992). }\end{array}$} \\
\hline & Free & 122 & \\
\hline & Independent & 114 & \\
\hline & Opportunity & 101 & \\
\hline & Ownership & 101 & \\
\hline & Sovereignty & 10 & \\
\hline \multirow{7}{*}{ Preservation } & Security & 190 & \multirow{7}{*}{$\begin{array}{l}\text { "...while retaining those } \\
\text { provisions essential for the } \\
\text { protection of national securi- } \\
\text { ty" (Conservative party, } \\
\text { 1974). } \\
\text { "...improvements in respect } \\
\text { of conservation, and action } \\
\text { to prevent pollution" (La- } \\
\text { bour party, 1983). }\end{array}$} \\
\hline & Protect & 114 & \\
\hline & Restore & 63 & \\
\hline & Stability & 33 & \\
\hline & Conservation & 28 & \\
\hline & Sustain & 18 & \\
\hline & Safeguarding & 11 & \\
\hline \multirow{2}{*}{ Moral Values } & Dignity & 12 & \multirow{2}{*}{$\begin{array}{l}\text { "We will stand fully by our } \\
\text { obligations..." (Conserva- } \\
\text { tive 1987). }\end{array}$} \\
\hline & ligations & 11 & \\
\hline
\end{tabular}

Table 2: BPS

\subsection{A Comparison of the Utilization of Metaphoric Themes in BPS and APS}

Metaphors in political speech are usually implemented due to three core reasons, namely to induce certain emotions, convince the public, and appeal to voters through simplification of complex problems. The majority of themes listed in the previous section tends to involve a particular function in political discourse. The differences and similarities in the themes of BPS and APS serve as evidence of cultural specificities of both nations as well as the goals pursued by politicians using these speeches. The most significant themes of British and American corpora are analysed in the course of the present research. 


\subsubsection{Unity/Community}

The American corpus contains a wide variety of metaphors appealing to unity and the need of unification in order to gain certain goals. The word "together" was the most commonly used metaphor among all American inaugural speeches from 1974 to 1997. The speakers appealed to the connectedness and the ability of the entire country to act as one. Such need to utilize the ideas of unity stems from the intention of the U.S. politicians to delegate responsibility on the public. Additionally, it roots in the political system of the country, where the federal government does not have full-range power. In the multicultural country, the ideas of community are essential for the political officials in terms of the need to control the public (Pinaire 2008).

In British corpus, the topic of unity is not that evident. It relates to the different domain; when applied "community", BPS appeals to the workers and public not with the intention to underline the connectivity among Britons, but to the individual citizens. The words used in the metaphoric expressions of the British corpus are distinctive from those of APS in terms of political context. For example, “... which compel offenders to make amends by doing useful work for the local community" (Conservative party 1983). Such metaphors in the BPS serve as the tool for calling to the British public, and despite the fact that the theme of community is the most frequently used in the BPS, it does not convey the ideas of unity. According to Hofstede (Hofstede 2006), the level of individualism is high for both Britain and U.S., yet, as the current results reveal, the APS contains more metaphors appealing to the ideas of unity than BPS.

In APS, the political speakers appeal to public as 'children', 'citizens', 'fellows' that also represent the attitude of the officials to the population, which especially evident in appellations like 'children' who need constant 'guidance'. It is possible to notice the intention of the politicians to impose their agenda and the desire to increase power, which is also demonstrated in the metaphors calling to authority.

\subsubsection{Religion}

At this point, it has to be noted that unlike APS, BPS does not contain any religious metaphors. At the same time, American corpus is rich in religious metaphoric expressions with some of the speakers citing Bible in their speeches. For instance, in his inaugural speech Jimmy Carter cited Bible, "he hath showed thee, O man, what is good; and what doth the Lord requires of thee, but to do justly, and to love mercy, and to walk humbly with thy God" claiming that his mission as a President will follow the rules of the Book (Carter 1977). In his second inaugural speech, Ronald Reagan appealed to the religious concept emphasizing that "in this blessed land, there is always a better tomorrow" (Reagan 1985).

According to Hofstede's framework, the U.S. has a low rate in low-term orientation meaning that the culture has a strong line between 'good' and 'evil', right and wrong, which can root in the strong religious impact on the American culture (Mooij $\&$ Hofstede 2011). Throughout the American corpus, the metaphors calling to Christian religious beliefs are in abundance that also points to the inability of the atheists or the representatives of the other confessions to occupy powerful political positions in the U.S. (Kettell 2013). In the BPS, the speakers mentioned metaphors appealing to the moral values, however, they included them quite rarely (Lawrence, 2007). It is possible to put this theme in the same category as religion, as British politicians use it for the same purposes. 


\subsubsection{Power/Authority/Difficulties}

In both American and British corpora, the metaphors appealing to power are very common and implemented frequently. According to Kimmel (Kimmel 2004), the utilization of such metaphoric expressions reinforces the position of a speaker and empowers the listeners essential for the inspiration of voters. Moreover, the application of such metaphors in political speech is considered to be universal for the speakers all over the world. At the same time, the meaning between the American and British corpora varies. For example, George Bush by emphasizing that "there is but one just use of power, and it is to serve people" (Bush, 1989) tries to induce trust of his voters. At the same time, Bill Clinton used the 'power' metaphor to mark the changes in the economic environment claiming that "profound and powerful forces are shaking and remaking our world..." (Clinton 1993). In this way, Clinton tried to cause fear and uncertainty of the external 'powerful forces' in order to justify his following actions in the international arena. As Hofstede's framework claimed, the U.S. citizens tend to be suspicious to changes, therefore, they tend to induce negative and unpleasant feelings (Mooij \& Hofstede 2011).

In the American corpus, the metaphoric expressions representing difficulties are not in abundance but still are used frequently. For the U.S. speakers, difficulties are 'challenges' and 'struggles', but never 'obstacles' or even 'difficulties', because the concepts of a challenge and a struggle represent a test that has to be undergone. Otherwise, to reveal that something is difficult means to recognize personal weakness, which is not allowed in the political speech.

British speakers used the metaphor of power for encouraging voters and in order to justify their political programs "the Commonwealth took on a new role as a promoter of democracy the rule of law, and respect for individual freedoms" (Conservative party 1992). At the same time, it is possible to mention that the Labour party tended to use fewer metaphors appealing to authority. In the other cases, BPS includes a direct appellation to the power of the elected officials or the promises to give power to ordinary people.

\subsubsection{Freedom / Preservation / Devotion}

It was decided to unite several themes in one section due to the similarity of these topics. The metaphors appealing to freedom and liberty are similar in both British and American corpora. The meaning the politicians from both countries encapsulate in these metaphors is practically the same. For example, Jimmy Carter acclaimed that "the passion for freedom is on the rise" (Carter 1977); Labour party in 1997 promised "freedom of information and guaranteed human rights" (Labour party 1997). Both speakers referred to the same strivings of random citizens to have power making decisions for their country and themselves. The majority of political speakers in the West choose to use these metaphors for consolidating their power in the office (Petrica 2014).

The APS includes the metaphors appealing to devotion, usually applied in order to demonstrate the desire of the official to serve his country or for inducing the sense of patriotism among voters. For example, "duty, sacrifice, commitment, and patriotism that finds its expression in taking part and pitching in" (Bush 1989). In this sentence, George Bush uses the metaphors to induce the sense of patriotism and devotion of the people. BPS does not contain the same topic, yet, British corpus includes a lot of metaphors that appeal to preservation and retention. For instance, it was claimed that "... the spirit of our people restored the reputation of our country" (Conservative party 1987). Here, the Conservatives appeal to the past of the country and the necessi- 
ty to protect, secure, and restore the values of the previous generation. It was admitted that in the British culture, the topic of preservation of the traditions and customs is essential for the politicians, especially Conservatives, using them quite frequently.

\subsubsection{Motion/Stimulation}

In American corpus the metaphors addressing motion are common; this fact was also noticed by the previous research. Xu (2010) claimed that the metaphors appealing to journey and motion come from the belief that the Americans are travellers; Penninck (Penninck 2014) considers that such metaphors may represent a necessity to get over a difficult situation, like the economic crisis. Reagan's acclamation of "as we continue our journey, we think of those who travelled before us" (Reagan 1985) represents an example of the symbolic meaning of the journey, which is more appealing to the assumption made by $\mathrm{Xu}$ (Xu 2010). Additionally, this metaphor has existential meaning illustrating a connection between the previous and current generations.

In BPS, there are no metaphors of similar topic, but there are plenty of them trying to encourage the listeners for the motion. In some instances, the officials tended to use these metaphors for delegating power and/or responsibility to the public. The politicians use the stimulation for action by claiming that "further changes may be needed to encourage people..." (Conservative party 1979). Labour party admitted that "we are a national party, supported today by people from all walks of life" (Labour party 1997), which partially delegates the power and responsibility for their further actions to their supporters as well.

\section{Summary}

After analysing American and English corpora, it was possible to notice that there were no radical differences in them. At the same time, several significant distinctions were found. APS is rich in Biblical metaphors that are frequently utilized by all speakers. BPS does not contain a single metaphoric expression linking to religion, which means that in the U.S. Christianity still has a strong impact on citizens while the British culture emphasizes moral values aside the religion. Another crucial difference concerns the ideas of connectedness and unity fostered by the American inaugural speeches, which was absent in the British corpora. Instead, BPS addresses people in general not insisting on the need to unite for certain goals. The frequency of implementation by the American speakers of such ideas points to the strong sense of nationalism of the U.S. citizens, so as the metaphors dedicated to the concept of devotion.

Other themes raised by metaphors are more or less similar for both BPS and APS. Both corpora appeal to motion or tend to stimulate actions; they also include the metaphors of liberty and freedom. Politicians from both nations address the same values common to the U.S. and Britain, namely independence, democracy, and peace. At the same time, British corpus contains fewer metaphoric expressions than the American one. The language of BPS is more straightforward and addresses certain issues, problems, and purposes of a particular situation, while APS includes a wide variety of poetic tools, including metaphors. At the same time, the character of inaugural speeches and political manifestos is different a priori. Newly-elected American presidents have to consolidate their position among the voters, so as to justify their actions and honour his pledges while a party manifesto has to address particular problems and propose effective solutions. Thus, metaphors are less popular in the British 
tradition of political speech. Yet, in the U.S. culture, it is considered that the oratory skills are essential for the presidents.

After the analysis of metaphors in the British and American corpora, it is possible to make a conclusion that while both cultures are similar, there are certain differences between the speeches that emphasize the distinctions among the goals of both political powers. Metaphors discovered in the APS aim to appeal to the emotions of the citizens, their background, the sense of unity, and Western values based on the Christianity. BPS has the purpose of convincing the public that urgent problems will be resolved by the chosen political power. Such application of metaphor appeals to the ability of the voters to understand, rather than to feel. At this point, it is important to remember that the U.S. and British political systems have radical differences with the last being more homogeneous in terms of culture. However, while being a multicultural nation, the U.S. tends to appeal mostly to the values yielded on the Christian foundation. The utilization of metaphors varies among the speakers, which points to the personal preferences and time period when the speeches were written.

At the same time, the current research has several limitations that do not allow making certain assumptions easily. First of all, the quantity of materials chosen for the APS is smaller than the one selected for the BPS. Yet, it was impossible not to consider both political parties in the BPS, as these materials differ in meaning. It would also create a limitation due to the fact that American presidents were affiliated with two distinctive parties as well. Therefore, it is important to take into account the discrepancies in the frequency of utilization of metaphors. It is believed by the researchers that this limitation did not affect dramatically the current study. Nevertheless, due to differences in quantity, it is difficult to explore the distinctions/similarities in the meaning of metaphors used by conservative representatives and republican presidents or Labour party and democratic presidents due to the resemblance in their political views.

Therefore, the future research may compare the metaphors used by the candidates of several parties in the U.S. and Britain with the utilization of quantitative research methodology. It is considered that the survey may be helpful in the further exploration of this subject, as it can present the relationship between variables. In addition, it is recommended to examine more recent political speeches comparing them with the past ones in regard to the metaphoric expression and frequency of their usage. Future research may explore the political speech of the officials in a certain problem, like the economic crisis, armed conflict or the outbreak of a disease.

\section{Bibliographic references}

BENOIT, W. L. 2001. Framing through Temporal Metaphor: The "Bridges" of Bob Dole and Bill Clinton in Their 1996 Acceptance Addresses. Lanham: Rowman \& Littlefield Publishers, Inc. ISBN 0-7425-2914-2.

BURKE, K. 1973. The Philosophy of Literary Form. Berkeley: University of California Press. ISBN 0520024834.

CHILTON, P. 2004. Analysing Political Discourse: Theory and Practice. London: Routledge. ISBN 978-0415314725.

GUTTENPLAN, S., 2005. Objects of Metaphor. Oxford: Clarendon Press. ISBN 9780199280896.

HOFSTEDE, G. J. 2006. Political Correctness: Words as Weapons. In: Business Renaissance Quarterly, vol. 1, n. 1, pp. 59-74. ISSN 1930-7462. 
KIMMEL, M. 2004. Metaphor Variation in Cultural Context: Perspectives from Anthropology. In: European Journal of English Studies, vol. 8, n. 3, pp. 275-293. ISSN 1744-4233.

KÖVECSES, Z. 2002. Metaphor: A Practical Introduction. New York: Oxford University Press. ISBN 978-0-19-537494-0.

LAKOFF, G. - JOHNSON, M. 2003. Metaphors We Live By. Chicago, IL: University of Chicago Press. ISBN 9780226468013.

LAWRENCE, J. S. 2007. Republicanism, Religion, and the Soul of America/a Nation of Religions: The Politics of Pluralism in Multi-religious America. In: Journal of American Culture, vol. 30, n. 1, pp. 132-147. ISSN 1542-734X.

MIO, J. S. 1996. Metaphor. Implications and Applications. Mahwah, NJ: Lawrence Erlbaum Associates. ISBN 0-8058-1650-X.

MOOIJ, M., HOFSTEDE, G. 2011. Cross-Cultural Research: A Review of Findings. In: Journal of International Consumer Marketing, vol. 23, pp. 181-192. ISSN 15287068.

MUELLER, R. 2010. Critical analysis of creative metaphors in political speeches. In: Researching and applying metaphor in the real world. vol. 26, n. 12, pp. 321-332. ISBN 9789027223807.

PENNINK, H. 2014. An analysis of metaphor used in political speeches responding to the financial crises of 1929 and 2008. Gent: University Gent.

PEREZ, R. G. 2008. A Cross-Cultural Analysis of Heart Metaphors. In: Revista Alicantina de Estudios Ingleses, no. 21, pp. 25-56. ISSN 0214-4808.

PETRICA, M. 2014. Cognitive Metaphors in Political Discourse in the Case of EUMembership Debate. Munich: Ludwig-Maximilians-Universität, pp. 1-17.

PINAIRE, B. K. 2008. The Constitution of Electoral Speech Law: The Supreme Court and Freedom of Expression in Campaigns and Elections. Stanford, CA: Stanford Law Books. ISBN 9780804757249.

SCHROOTS, J. J. F. 1991. Metaphors of aging and complexity. In: Metaphors of aging in science and humanities, vol. 3, n. 5, pp. 219-243. ISBN 082617440X.

TAYLOR, J. R. 1989. Linguistic categorization: Prototypes in linguistic theory. Oxford: Clarendon Press. ISBN 978-0198239185.

YU, N. 1998. The contemporary theory of metaphor: A perspective from Chinese. Amsterdam: John Benjamins Publishing Company. ISBN 9789027223531.

XU, H. 2010. Conceptual Metaphor in American Presidential Inaugural Addresses. In: Theory and Practice in Language Studies, vol. 3, n. 4, pp. 678-683. ISSN 1799-2591.

Words: 5977

Characters: 38115 (21, 17 standard pages)

Igor Ivanović, Doctor of Philology

Faculty of Philology

University of Montenegro

Danila Bojovića bb, 81400 Nikšić

Montenegro

iggybosnia@gmail.com 